\title{
PRODUÇÃO DE CONHECIMENTO GEOGRÁFICO VIRTUAL: ABORDAGENS SOBRE TEMPO/ESPAÇO ${ }^{1}$
}

\author{
VIRTUAL GEOGRAPHIC KNOWLEDGE PRODUCTION: APPROACHES ON TIME/SPACE
}

\author{
Antônia Márcia Duarte Queiroz \\ Universidade Federal de Uberlândia (UFU), Uberlândia, MG, Brasil, amdqueiroz@yahoo.com.br \\ Rosselvelt José Santos \\ Universidade Federal de Uberlândia (UFU), Uberlândia, MG, Brasil, rosselvelt@ufu.br
}

\begin{abstract}
RESUMO
A intenção desse texto é expor algumas discussões sobre a produção de conhecimento virtual que vem se desenvolvendo por meio da Educação a Distancia- EaD. Para esse fim analisa-se as categorias geográficas tempo/espaço na perspectiva do materialismo-histórico. O objetivo principal é contribuir na elaboração de conceitos, compreensão e busca de caminhos que possam trazer a prática da ciência à luz dos acontecimentos geográficos sob a perspectiva tecnológica e, das novas construções epistemológicas a partir da prática de ensino geográfico on-line. Nesse sentido, reflete-se sobre as Tecnologias de Informação- TICs, com vistas à elaboração de argumentos que fundamentem o tema da pesquisa de doutorado, Abordagens epistemológicas sobre a Geografia virtual no norte de Minas Gerais, que está sendo desenvolvida na Universidade Federal de UberlândiaMG. Sem esgotar o assunto, para essa abordagem utiliza-se de análises de tempo/espaço desenvolvidas em algumas obras de Milton Santos e, da obra condição pós-moderna de David Harvey. Por meio dessa análise foi possível refletir sobre novas percepções de tempo/espaço que se apresentam instantaneamente nas redes virtuais oriundas das transformações atuais da sociedade.
\end{abstract}

Palavras-chave: Epistemologia. TIC. Ensino. Geografia. Virtual.

\begin{abstract}
The intention of this text is to expose some discussions on the production of virtual knowledge that has been developing through distance-Learning education-EaD. For this purpose analyzed the geographical categories time/space from the perspective of historical materialism. The main objective is to contribute to the development of concepts, understanding and finding ways to bring the practice of science in the light of geographical events and technological perspective, the new epistemological constructions from the practice of geographic education online. In this sense, is reflected on the ICTInformation technologies, with a view to drawing up arguments to support the doctoral research issue, Abordagens epistemológicas sobre a Geografia virtual no norte de Minas Gerais, which is being developed at the Universidade Federal de Uberlândia- MG. Without exhaustive, this approach uses time/space analysis developed in some works of Milton Santos and, from post-modern condition of David Harvey. Through this analysis it was possible to reflect new perceptions of time/space that appear instantly in the virtual networks from the current transformations of society.
\end{abstract}

Keywords: TIC. Teaching. Geography. Virtual.

Artigo recebido para publicação em janeiro de 2015

Artigo aceito para publicação em junho de 2015

\section{INTRODUÇÃO}

A intenção de discutir sobre as categorias tempo e espaço se deve as transformações tecnológicas que aproximam os indivíduos no tempo, por meio da tecnologia on-line, que significa está em contato

\footnotetext{
1 Análises parciais/Tese de Doutorado: Abordagens Epistemológicas sobre a Educação Virtual em Geografia no Norte de Minas Gerais Universidade Federal de Uberlândia, 2013.
} 
imediato no mesmo instante em várias partes do mundo, ou seja, o individuo está em espaços diferentes pelo mundo, mas está tecendo uma rede de conhecimento em tempo real. Então se pode afirmar que o tempo e o espaço ora estão juntos e, ora podem está totalmente separados por meio da tecnologia virtual.

Essa nova forma de produção de conhecimento por meio das TICs requer reflexões, principalmente no campo do ensino da Geografia, pois se mostra em constante transformação didática pedagógica, tanto para a prática docente, como para a produção de conhecimento discente.

Para análise das categorias geográficas tempo/espaço, nessa abordagem utiliza-se dos autores Milton Santos e David Harvey, pois foram trabalhos construídos, a luz do método materialismo- histórico, que traçam dialeticamente linhas de reflexões a partir das transformações históricas da sociedade, principalmente da técnica para produção capitalista. As análises desses autores são passíveis de articulações a produção do conhecimento virtual geográfico e as mudanças na compreensão do tempo/espaço direcionado ao tema proposto na pesquisa supracitada.

Assim, na primeira seção foi necessário fazer um resgate do método para apresentar o objeto de análise desse texto, ou seja, discuti construções epistemológicas que se desenvolvem a partir das mudanças na sociedade que, na atualidade se apresenta por meio das TICs por meio do acesso crescente a informática e a internet, as quais possibilitaram o desenvolvimento da Educação à Distância (EaD) no mundo e, no Brasil.

Na segunda, apresentam-se as análises de tempo e espaço elaborados nas discussões epistemológicas de algumas obras de Milton Santos. E, também discute-se tempo e espaço nas análises de David Harvey (1996) na obra Condição Pós- Moderna.

A terceira seção apresenta-se linhas de reflexões sobre o desenvolvimento das TICs no ensino geográfico virtual que transformam as percepções no método de análise das categorias tempo e espaço, por meio das novas perspectivas tecidas nas redes virtuais para o ensino da Geografia. 
E, por fim as considerações finais que traz a luz reflexões da atualidade com suas construções de novos paradigmas oriundos das TICs que transformam a concepção de tempo e espaço para o ensino virtual e aprendizagem geográfica.

\section{Método: resgate para compreensão do tempo/espaço geográfico virtual}

Para compreensão geográfica do tempo/espaço que se deseja discutir nessa abordagem é necessário apontar alguns exemplos relevantes de métodos que têm orientado as pesquisas nas diversas áreas do conhecimento dentre eles pode-se citar: O Positivismo- principal expoente Auguste Comte (17981857). Para Comte, "o espírito positivo estabelece as ciências como investigação do real, do certo, do indubitável e do determinado". É possível afirmar também que a partir da visão de Comte "a imaginação e a argumentação ficam subordinados à observação.”. E ainda, "considerando que a observação é limitada, o conhecimento pode apreender fatos isolados" (RICHARDSON, 1999, p.33). A Fenomenologia tem em Edmund Husserl (1859-1938) um dos seus principais conceitos.

A fenomenologia pode ser definida como estudo das essências, e todos os problemas, segundo ela, tornam a definir essências: a essência da percepção, a essência da consciência (TRIVINOS, 1987, p.43); O estruturalismo parte do pressuposto de que cada sistema é um jogo de oposições, presenças e ausências, constituindo uma estrutura, onde o todo e as partes são interdependentes, de tal forma que as modificações que ocorrem num dos elementos constituintes implica a modificação de cada um dos outros e do próprio conjunto (GIL, 1999, p.37); e A visão holística parte do principio de que a compreensão do significado do fenômeno ou evento só é possível em função da compreensão das interrelações que emergem de um dado contexto.

A abordagem indutiva pode ser definida como aquela que o pesquisador parte de observações mais livres, deixando que as dimensões e categorias de interesses emerjam progressivamente durante os processos de coleta e análises de dados. Finalmente, a investigação naturalística é aquela em que a intervenção do pesquisador no contexto observado é reduzida ao mínimo (ALVES MAZZOTTI, 1998, p. 131), O Funcionalismo - principais contribuições estão apresentadas nos trabalhos de Herbert 
Spencer (1820-1903), Émile Durkheim (1858-1917) e Bronislaw Malinowski (1884-1942). Os pensadores "procuraram estabelecer analogias entre as formas de organização cultural e social e organismos vivos". Malinowski irá consolidar o funcionalismo "método de investigação social" (GIL, 1999, p. 36). O Estruturalismo - suas origens encontram-se no campo da linguística a partir dos trabalhos de Ferdinand Saussure (1857-1913) e do antropólogo Lèvi Strauss (1908-2009), O Compreensivo - Max Weber (1864-1920) contrário à utilização dos “métodos das ciências naturais no estudo da sociedade", por sua vez irá propor em seu lugar "apreensão empática do sentido finalista de uma ação, parcial ou inteiramente oriunda de motivações irracionais". O que significa dizer que "este procedimento a que ele chama de compreensão envolve uma reconstrução no sentido subjetivo original da ação e do reconhecimento da parcialidade da visão do observador".

O método Materialismo Histórico de Karl Marx (1818-1883) e Friedrich Engels (1820-1895) é considerado como a ciência filosófica do marxismo que estuda as leis sociológicas que caracterizam a vida da sociedade, de sua evolução histórica e da prática social dos homens, no desenvolvimento da humanidade. O materialismo histórico significou uma mudança. "fundamental na interpretação dos fenômenos sociais que, até o nascimento do marxismo, se apoiava em concepções idealistas da sociedade humana" (TRIVINOS, 1987, p.51).

A descrição supracitada se fez necessária à medida que se considera que em cada período histórico surge um método ou, métodos de análise epistemológica na busca da compreensão das transformações na sociedade. Assim é pertinente observar que o materialismo-histórico atende às necessidades paradigmáticas, como arcabouço nessa discussão, pois se revela ao tentar interpretar os fenômenos sociais oriundos das transformações na sociedade de produção capitalista. Essas transformações se apresentam, na atualidade pelo avanço das Tecnologias de Informação e Comunicação - TICs e culminam na atualidade em mudanças significativas nos modos de vida e na produção do conhecimento que se desenvolve por meio da educação a distância - EaD.

Nesse contexto as categorias geográficas tempo/espaço podem ser interpretadas a partir das transformações da sociedade inseridas nas TICs que culminou no ensino de geografia on-line. Essa 
transformação altera a forma de produção do conhecimento, à medida que constrói em si, tempo instantâneo e espaços virtuais de produção de conhecimento que modifica o ensino-aprendizagem pela rapidez das informações e necessidade de compreensão e retorno dessas informações com maior rapidez e agilidade.

As análises de autores que desenvolvem suas investigações ancoradas no materialismo histórico, como Milton Santos e David Harvey trazem pistas para que se desenvolvam linhas de reflexões epistemológicas inerentes as novas possibilidades de inovações do conhecimento a partir das redes de ensino virtuais.

\section{Tempo/espaço em obras de Milton Santos e David Harvey}

Lustosa (2011) após se debruçar sobre algumas obras de Milton Santos, dentre elas os livros Espaço e Método (1997), Espaço e Sociedade (1979) e Natureza do Espaço (2006), afirma que o posicionamento desse autor quanto ao método recorre ao marxismo e acrescenta que o espaço de acordo com Santos (1997), tem se forma, função, processo e estrutura, ou seja, o espaço tem uma história, nas palavras de Santos o espaço tem "uma vida".

Portanto, existe um processo de formação e transformação do espaço que, a partir de 1980 com as novas conjunturas políticas e sociais no mundo, Santos abandona, em parte, essas categorias de análise forma, função, processo e estrutura e passa a analisar o espaço fragmentado, as redes formadas pelas empresas globais e na comunicação de massa. Santos (2006) visualiza um novo período da história, o período técnico-científico informacional, a informação, o conhecimento instantâneo, o desenvolvimento da microeletrônica e da informática.

Assim, Lustosa (2011) entende o espaço de Santos como um verdadeiro híbrido que a partir dos anos de 1990, nas análises sobre a globalização perversa mostra que houve um desencadeamento da desigualdade social e, sugeri a busca de uma globalização com possibilidades para todos por meio da informática e da valorização da inteligência. Essa argumentação mostra o espaço dentro da ótica 
materialista histórica, ora provido de fronteiras físicas ou subjetivas a luz dos movimentos sociais, ora servindo a princípios das necessidades capitalistas desprovido de fronteiras.

Seguindo essa premissa pode-se afirmar que Santos (1994) em suas análises considera que: por tempo, vamos entender grosseiramente o transcurso, a sucessão dos eventos e sua trama. Por espaço vamos entender o meio, o lugar material da possibilidade dos eventos e em cada momento, mudam juntos o tempo, o espaço e o mundo. Tempo, espaço e mundo são realidades históricas, que devem ser intelectualmente reconstruídas em termos de sistema, isto é, como mutuamente conversíveis, se a nossa preocupação epistemológica é totalizadora. Em qualquer momento, o ponto de partida é a sociedade humana realizando-se. Essa realização dá-se sobre uma base material: o espaço e seu uso, o tempo e seu uso; a materialidade e suas diversas formas, as ações e suas diversas feições.

\footnotetext{
$\mathrm{Na}$ verdade, o tempo e o espaço não se tornaram vazios ou fantasmagóricos como pensou $\mathrm{A}$ Giddens, mas, ao contrário, por meio do lugar e do cotidiano, o tempo e o espaço, que contêm a variedade das coisas e das ações, também incluem a multiplicidade infinita de perspectivas. Basta não considerar o espaço como simples materialidade, isto é, o domínio da necessidade, mas como teatro obrigatório da ação, isto é, o domínio da liberdade (SANTOS, 1994, p. 17).
}

Para Santos (1994) o momento da história no qual chegamos à possibilidade de uma noção concreta de espaço-mundo e de tempo-mundo, um tempo cheio e um espaço cheio, uma totalidade empírica. Então chegamos a essa ideia de mundo- mundo, de uma verdadeira globalização da Terra, exatamente a partir dessa comunidade mundial, impossível sem a mencionada unicidade das técnicas, que levou à unificação do espaço em termos globais e à unificação do tempo em termos globais. O espaço é tornado único, à medida que os lugares se globalizam. Cada lugar, não importa onde se encontre, revela o mundo (no que ele é, mas também naquilo que ele não é), já que todos os lugares são suscetíveis de intercomunicação. Mas o tempo é também unificado pela generalização de necessidades fundamentais à vida do homem, de gostos e desejos, tornados comuns em escala do mundo. Estas limitam a concretização das ocasiões. "Ciência, tecnologia e informação são a base técnica da vida social atual e desse modo devem participar das construções epistemológicas renovadoras das disciplinas históricas (SANTOS, 1994, p.20). 
O autor acrescenta que na realidade, o tempo do lugar é um conjunto de tempos dentro desse tempo do lugar, que corresponde a possibilidades diferentes dos indivíduos - mas não somente dos indivíduos, como também das empresas - de utilização do tempo e do espaço. Além disso, afirma que:

A questão do tempo e da materialidade do espaço deve ser estudada pelo problema técnico. As técnicas é que trazem a definição de materialidade. Exagerando, diríamos que até a própria natureza poderia ser estudada do ponto de vista técnico - é um certo exagero, licença poética. E o evento, que é a sociedade, vai se encaixando nesses objetos. Ternos então, de um lado, o tempo das ações e, de outro o tempo da materialidade. É assim que penso na associação das noções "de tempo e espaço. As ações são uma possibilidade vaga ou concreta oferecida por um momento preciso da história (SANTOS, 1994, p. 91).

As análises de tempo e espaço sob a ótica de Milton Santos se apresenta a partir dos pressupostos filosóficos que busca no movimento histórico do homem na sociedade, suas relações de trabalho, sociais, políticas e culturais paradigmas para definir as seus contornos e área de abrangência. A técnica foi utilizada por Santos para desenvolver linhas de reflexões sobre conceitos de tempo e espaço.

Nas ideias de Milton Santos (2002: 264-265) que lembra a grande aplicabilidade do conceito de redes, a sua ampla utilização a qual afrouxa seu sentido e, por isso, deveriam ser conformadas a dois únicos significados: aquele que considera apenas sua realidade material, ou seja, o conjunto de objetos criados em diferentes épocas, que, fixos no espaço, articulam os locais, e o outro, que considera a rede também como um dado social ou político, formado pelas pessoas, informações e valores que por ela circulam.

Assim, utiliza-se dessas análises para afirmar que as TICs trouxeram novas abordagens de discussão epistemológica de tempo e espaço a partir do ensino virtual, de modo geral e, principalmente do ensino da geografia virtual, disponibilizadas por meio da educação à distância. Portanto o tempo e o espaço adquirem novas formas de análise à medida que o uso da TIC, por meio do computador e as redes virtuais, produzidas pela internet permitem o tempo de construção de conhecimento instantâneo em espaços distintos, em qualquer parte do mundo, o que significa uma separação entre tempo/espaço; Ou, também pode apresentar a troca de experiências e de conhecimentos em um mesmo espaço, ligado por redes virtuais. 
Essa afirmação separa o tempo e o espaço e se difere das discussões epistemológicas do método de análise do espaço nas obras de Milton Santos que aproxima tempo e espaço. Nesse caso, como exemplo pode-se citar as aulas por videoconferência ou laboratórios coletivos de pesquisa informatizada que por meio das redes virtuais podem transmitir e trocar informações em tempo real, em qualquer parte do mundo.

David Harvey (1996) na obra Condição Pós-Moderna analisa as relações de mudança do capital a partir da dialética tempo/espaço. Assim, as forças motrizes da história na produção da sobrevivência dos homens assumem dimensões do espaço e do tempo que se tornam relevantes.

Nesse contexto Harvey (1996) afirma que a reprodução da vida social é criada através de processos materiais através do tempo e espaço. Para Harvey o capital atua dialeticamente com o espaço, por meio da industrialização e da urbanização e, o tempo a partir do século XIX foi responsável pela modernização do capitalismo na "chamada era Fordista". O tempo, então, nesse sentido foi considerado como símbolo de riqueza, de agilidade no processo de produção, e o espaço foi considerado como estático, fixo e não dialético.

Harvey (1996) esclarece, apesar de o tempo está sempre em movimento e o espaço está imóvel, os dois não podem ser compreendidos separados da ação social, sempre variam e alteram as posturas individuais e coletivas de forma global e, primordialmente sem fronteiras. $\mathrm{O}$ autor acrescenta que esse fruto espaço-temporal da pós-modernidade está marcado por meio de inovações nas condições de trabalho e na produção de imagem de distintos significados com grande poder de imaginação.

Esse argumento de Harvey (1996) mostra que as relações de produção são responsáveis por determinar o tempo e o espaço. As novas modalidades produtivas surgem agregadas a mecanismos de produção, mercado e consumo que se movimentam em forma de financiamentos globalizados de capital especulativos, fictício, descentralizado com o poder de inserir ou excluir mercados competitivos. Esse constante movimento assume configuração a partir de modelos primitivos ou modernos, de acordo com o contexto o qual está inserido, independente de abordagem temporal ou espacial. 
Segundo Vesentini (2008) Harvey utilizou-se de um esquema lógico-formal que denega as contradições inerentes às indeterminações do objeto estudado, ignorando as contradições históricas e as lutas sociais, porém ressalta que, no final dos anos 1960 Harvey propunha um novo paradigma mais qualitativo e crítico, pois a Geografia não se presta a fórmulas simples, mas sim sempre demanda explicações longas e complexas que nunca esgotam o tema estudado.

A importância desse resgate do método de análise de Santos e Harvey serviram para mostrar como esses autores se utilizaram das categorias geográficas tempo e espaço. Portanto pode-se afirmar que na perspectiva de David Harvey o tempo e o espaço se interagem de forma dialética por meio da ação social, de forma global e sem fronteiras, marcada por meio de inovações nas condições de trabalho e, na produção de imagem de distintos significados com grande poder de imaginação, mostra uma dialética entre tempo e espaço que dependendo da sua representação pode ser de forma global e desprovido de fronteiras. Na perspectiva de Milton Santos vislumbra possibilidades de tempo e espaço que podem ou não produzir fronteiras em consequência das relações da sociedade.

Assim, tempo/espaço podem ser categorias importantes que podem servir como método de análise na busca da compreensão das novas construções de conhecimento oriundos do ensino da Geografia virtual. Portanto é possível afirmar que a partir do desenvolvimento das TICs, as relações de produção da sociedade tornam-se responsáveis em definir formas promissoras da aquisição de conhecimento on-line que podem se apresentar com tempo instantâneo, por meio das tecnologias pelas redes da internet e, ao mesmo instante pode se apresentar independente do espaço que o individuo ocupa no planeta.

Esses pressupostos dependem das necessidades nas relações políticas e econômicas de reprodução do modelo capitalista vigente em cada momento histórico que atingem todo o planeta. É pertinente ressaltar que a produção de conhecimento em tempo real movimenta a educação, a economia, a política e as relações de produção, independente do espaço que o individuo ocupa no planeta.

\section{TIC: uma análise do conhecimento produzido nas redes de ensino geográfico virtual}


Essa abordagem utilizando das reflexões dos autores Milton Santos e David Harvey, em suas análises sobre tempo/espaço econômico-social servem de arcabouço para a análise tempo/espaço da pesquisa de doutorado, epistemologia da Geografia virtual na medida em que:

\footnotetext{
Qualquer teoria que de fato procure explicar ou construir algum objeto segundo os cânones científicos (algo que não tenha nada a ver com um método único excludente), qualquer pesquisa científica realizada de forma séria e honesta, sempre tem um valor que independe da opção metodológica do investigador. É por isso que os dois grandes nomes das ciências sociais da segunda metade do século XIX até meados do século XX foram Marx e Weber, dois personagens com opções éticas e ideológicas bastante distintas, mas que produziram importantes obras que já foram utilizadas por autores com diferentes concepções- na Economia, na Sociologia, na Ciência política, na história e mesmo na Geografia (VESENTINI, 2008, P.21).
}

Para Vesentini (2008), o avanço do conhecimento, em especial o científico, não se faz tão somente com a descoberta de novos aspectos da realidade, de novos fenômenos ou de encadeamentos entre os mesmos, enfim de novos achados sobre os objetos estudados ou mesmo da (re)construção dos objetos ou da invenção de novos. Ele também ocorre em oposição a modelos ou esquemas de pensamento dominantes e/ou tradicionais, no confronto com as ideias estabelecidas e constantemente reproduzidas.

Assim, também é relevante a seguinte afirmação:

O espaço, enquanto recurso humano limitado e desigualmente distribuído constitui um local de confronto pela sua apropriação, interpretação e utilização por parte dos atores sociais, em regra inseridos em grupos sociais. O espaço por um lado, como o tempo constitui uma das condições e eixos inerentes à sociedade humana, por outro, a organização do espaço comporta a marca da ação humana. "As realidades espaciais constituem não só locais de reprodução social, como também testemunhos da memória colectiva de um agrupamento humano, do seu percurso histórico, das suas vicissitudes e contradições, não só internas como face ao exterior" (PORTAS, 2006, p.187).

Ao longo da história observam-se inúmeras modificações tecnológicas, oriundas da revolução técnica/cientifica. O século XXI é caracterizado como a era da informação, e consequentemente avanços na educação, o professor deixa de ser o "dono do saber" e passa a ser um mediador de informações entre os alunos, e o conhecimento que se renova, constrói-se e não é algo pronto e medido. Por isso, a utilização da tecnologia como instrumento do aprender a aprender tem sido um constante desafio para educadores contemporâneos. 
Marangon (2011, p. 40) afirma que "em contato com uma geração que já nasceu tendo intimidade com as novas tecnologias, o desafio do professor é ensinar a navegar entre inúmeras informações, selecioná-las de maneira crítica e organizá-las”. A educação, desde cedo, é permeada pela televisão, pelo videogame, pelo computador, pela internet e por tantos outros recursos eletrônicos. (MARANGON, 2011, p. 40). Há uma diversidade de recursos tecnológicos e textos que podem ser explorados por várias mídias, como enfatiza Teles (2003):

\footnotetext{
Além da internet, que torna possível todo tipo de pesquisa, troca de informações, temos os canais de televisão que se dedicam à História, Geografia, Biologia, Astronomia, Física, Química, etc. E ensinam artesanato, arte culinária, línguas estrangeiras e tudo mais. E convenhamos que esta é uma maneira muito mais agradável de se aprender (TELES, 2003, p. 17).
}

A informática é um facilitador e motivador na aprendizagem, já que oferecem muitos recursos aos seus usuários. Conforme Valente (1993, p. 06) O computador passa a ser uma ferramenta educacional, uma ferramenta de complementação, de aperfeiçoamento e de possível mudança na qualidade de ensino. Isto tem acontecido pela própria mudança na condição de vida e a natureza do conhecimento. 0 mundo, hoje é dominado pela informação e por processos que ocorrem de maneira muito rápida e imperceptível. Os fatos e alguns processos específicos rapidamente se tornam obsoletos e inúteis. Consoante com esse argumento, Santos por meio de suas investigações $(1994$, p. 7) afirma que:

\footnotetext{
Sem discurso, praticamente não entendemos nada. Como a inovação é permanente, todos os dias acordamos um pouco mais ignorantes e indefesos. A rainha Juliana da Holanda assistindo à demonstração de um computador eletrônico em uma exposição em Amsterdã exclamou: "Não posso entender isso. Nem posso entender as pessoas que entendem isso".
}

Segundo Almeida (2000, p.79), “o computador é uma máquina que possibilita listar ideias ou hipóteses, que levam a criação de um mundo abstrato e simbólico, que permite introduzir diferentes formas de atuação e interação entre as pessoas". Assim é importante destacar que a integração das tecnologias como TV, vídeo, computador, celular e outras mídias poderão promover no processo educacional mudanças significativas. Como ressalta Teles (2003, p.14), “a nossa proposta é transformar o homem para transformar a sociedade”. Corrobora com essa afirmação: “[...] formação espacial, reside no fato de se explicitar, teoricamente, que uma sociedade só se torna concreta através 
de seu espaço, do espaço que ela produz, por outro lado, o espaço é inteligível através da sociedade" (CORRÊA, 2001, p.26,27).

Assim o conhecimento Geográfico virtual pode se desenvolver por meio das TICs que se disseminam nas redes, possibilitando o tempo espaço, ora estarem juntos, ora separados (vide Figura 1).

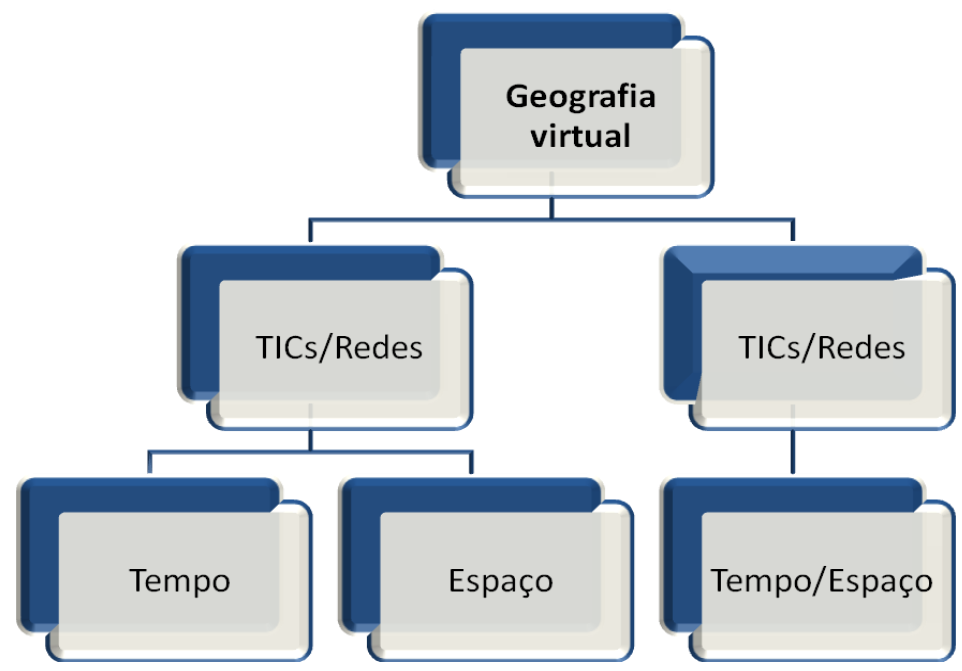

Figura 1. Organograma da Geografia Virtual.

Fonte: autoria própria.

A produção do conhecimento geográfico virtual independente do espaço fixo, mas sim depende da rede onde está conectado e a velocidade, ou seja, depende do tempo de acesso a essa produção e divulgação desse conhecimento. Nesse sentido, Dias (2001) afirma que o conceito de rede vem se construindo, nos anos recentes, numa agenda de pesquisa que reúne propostas, significados e abordagens disciplinares diversas. É um processo contínuo e complexo por interações locais e globais.

Os estudos em andamento nos permitem avançar mais uma hipótese: as qualidades de instantaneidade e de simultaneidade das redes de informação emergiram mediante a produção de novas complexidades no processo histórico. [...]"que redesenharam o mapa do mundo, dos países e das regiões. Processos de múltiplas ordens: de integração produtiva, de integração de mercados, de integração financeira, de integração da informação. Mas processos igualmente de desintegração, de exclusão de vastas superfícies do globo (DIAS, 2001, p.146).

Assim, para essa construção nas redes o tempo torna-se mais relevante e fundamental do que o espaço. Portanto o tempo e o espaço se apresentam em constante movimento, em um movimento dialético e cheio de novos significados. 
Matos (2005) mostra a importância das redes na atualidade que definem vários tipos de sistemas de relações e delas aprimora-se a visão dos desdobramentos espaciais causados por fenômenos políticos, sociais e econômicos, sejam desencadeados pelas transformações estruturais dadas pela formação da sociedade urbano-industrial em várias partes do mundo, sejam aqueles associados, mais recentemente, às novas materialidades e virtualidades advindas de processos globalizadores de "alargamento dos contextos". Evidencia-se variadas redes que organizam a produção, circulação de forma heterogênea de categorias diferentes de fluxos, usos, coesão, centralização e poder dos atores envolvidos.

Essas redes, na atualidade se movem a medida das necessidades que emergem na sociedade por meio das transformações tecnológicas que no ensino/aprendizagem, segundo Moran (1994) o uso das tecnologias faz total diferença na aprendizagem, quando são utilizadas de forma adequada pelo professor, principalmente a internet por ser uma tecnologia que permite o estímulo dos alunos, pela novidade e pelas possibilidades infinitas de pesquisa que oferece. As TICs podem ser responsáveis por modificações constantes nas formas de comunicação entre os povos.

De acordo com Pontara (2010, p. 234) os componentes da comunicação são: o emissor, o receptor, a mensagem, o canal de propagação, o meio de comunicação, a resposta (feedback) e o ambiente onde o processo comunicativo se realiza. Quanto à forma, a comunicação pode ser verbal, não-verbal e mediada. Assim a comunicação é o processo que envolve a transmissão e a recepção de mensagens entre uma fonte emissora e um destinatário receptor, no qual as informações, transmitidas por intermédio de recursos físicos (fala, audição, visão etc.) ou de aparelhos e dispositivos técnicos, são codificadas na fonte e decodificadas no destino com o uso de sistemas convencionados de signos ou símbolos sonoros, escritos, iconográficos, gestuais dentre outros. A comunicação é o alicerce para a formação educativa, especialmente nas possibilidades do diálogo, interação e interatividade.

Na concepção freireana, a educação é concebida como um ato político e de comunicação - e não de extensão -, pois a comunicação implica uma reciprocidade que não pode ser corrompida. "Comunicação é educação, é diálogo, na medida em que não é transferência de saber, mas um encontro de sujeitos 
interlocutores que buscam a significação dos significados" [...] (FREIRE, 2001, p. 67). A definição dessa reciprocidade pode ser resultante de novos arranjos espaço-sociais tais como:

As práticas espaciais resultam, de um lado, da consciência que o homem tem da diferenciação espacial. Consciência que está ancorada em padrões culturais próprios a cada tipo de sociedade e nas possibilidades técnicas disponíveis em cada momento, que fornecem significados distintos à natureza e à organização espacial previamente já diferenciadas (CORRÊEA, 2001, p.35).

Sob o império da informação e da tecnologia, sob o domínio da imagem e do som, a comunicação é eletrônica e se faz instantaneamente através da rede mundial de computadores, de aparelhos telefônicos cada vez mais elaborados, de sistemas digitalizados de transmissão de última geração.

Nas palavras de Umberto Eco (1997) nós precisamos de uma forma nova de competência crítica, uma arte ainda desconhecida de seleção e decodificação da informação, em resumo, uma sabedoria nova. A tecnologia de altíssimo nível utilizada pelos meios de comunicação reduziu drasticamente as distâncias entre os lugares, fazendo com que hoje os fatos e acontecimentos cheguem a qualquer parte do mundo, no mesmo instante de sua ocorrência.

$\mathrm{Na}$ atualidade assiste-se uma Educação Dialógica que visa preparar cidadãos que interajam com o mundo, entendam de temas mundiais e que possam transformar o seu futuro. Ou seja, compreender o local onde vive atuar nele e inventar um mundo melhor. Com o advento da globalização econômica, vem aumentando cada vez mais o fascínio que esse meio de comunicação de massa exerce sobre as pessoas e, especialmente, sobre o aprendiz.

O avanço tecnológico acelerado urge um mundo digital de assimilação e aprendizado por redes virtuais bem mais rapidamente e, em maior quantidade de informações, porque utiliza as capacidades audiovisuais em conjunto. Ambos combinam diferentes linguagens: imagens e ritmos, falas, músicas, sons e textos escritos.

\section{CONSIDERAÇÕES}


A contribuição epistemológica pode partir do método de análise do pesquisador, que nessa abordagem surge por meio das reflexões sobre as categorias geográficas tempo e espaço para compreensão da Geografia virtual. Essa análise se orienta partindo da premissa das discussões de Milton Santos, envolto nas redes de comunicação e novas tecnologias que podem ou não possuir fronteiras. Orienta-se também na perspectiva de David Harvey, que discutiu sobre o desenvolvimento capitalista por meio de análises sobre o espaço estático, mas o tempo em constante movimento na produção de bens.

Por meio dessas análises foi possível perceber que, na atualidade surgem novos paradigmas oriundos das TICs que transformam a concepção de tempo e espaço para o ensino e aprendizagem geográficos virtuais que revelam diferentes metodologias, gerando um processo de transformação didático pedagógico constante em que todos têm um papel importante a desempenhar. Esse papel na Geografia virtual se apresenta a partir da compreensão do método de análise escolhido pelo pesquisador que, necessariamente não precisa ser rigoroso e complexo, mas sim servir para apontar linhas de reflexão.

A linha de reflexão para análise tempo/espaço apresentadas por Santos e Harvey trouxe possibilidades de reflexão para compreensão da Geografia virtual e, além disso, trouxe pistas para uma posterior análise sobre as demais categorias geográficas. Portanto por meio das TICs o tempo torna-se virtual e pode proporcionar ao individuo construção e troca de conhecimento geográfico instantâneos em redes rápidas, capazes de se conectarem em tempo real, independente do espaço que o individuo ocupa.

A importância dessa análise permite refletir sobre o paradigma da geografia que alguns autores defendem em que consideram o tempo indissociável do espaço, pois, na atualidade há uma transformação possível para outra construção, que por meio das TICs podem tecer redes virtuais que podem separar o tempo e o espaço. Assim, o docente ou discente pode estar em qualquer espaço do planeta em tempo real, com contato instantâneo que permite que aconteça o ensino a distancia, por meio da produção e troca de conhecimento geográfico on-line.

A produção de conhecimento virtual pode interessar vários setores da sociedade, mas, principalmente atende aos interesses de produção de modo geral, de ensino, da economia e aos anseios políticos 
sociais. Essa troca de conhecimentos geográficos instantâneos requer outras investigações que serão desenvolvidas no decorrer desta pesquisa de doutorado.

\section{REFERÊNCIAS}

ALMEIDA, Maria Elizabeth Bianconcini de. Informática e formação de professores. Brasília: Ministério da Educação, 2000.

DIAS, Leila Chistina. Geografia: Conceitos e Temas. In: Iná Elias de Castro et al. 3. ed.Rio de Janeiro: Bertrand Brasil, 2001.

FREIRE, Paulo. Extensão ou Comunicação? Rio de Janeiro: Paz e Terra, 2001

GIL, Antônio Carlos. Métodos e técnicas de pesquisa. 5. Ed. São Paulo: Atlas, 1999.

LUSTOSA, Cesar Augusto. Milton Santos e o método de pesquisa em Geografia. Revista eletrônica: Tempo- TécnicaTerritório, v. 2,N. 1, 49-59, 2011.

MARANGON, Cristiane. Crianças na era digital. Revista Pátio Educação Infantil, v. 28, p. 40-43, 2011.

MAZZOTTI, Alda Judith Alves; GEWANDSZNAJDER, Fernando. O Método nas ciências naturais e sociais: Pesquisa quantitativa e qualitativa. 2a ed. São Paulo: Pioneira, 1998.

MORAN, José Manuel. Novos caminhos do ensino à distância. Informe CEAD - Centro de Educação à Distância, Rio de Janeiro, a. 1, n. 5, p. 1-3, out/nov/dez 1994.

MORAN, José Manuel. Interferências dos meios de comunicação no nosso conhecimento. Revista INTERCOM: Revista Brasileira de Comunicação, São Paulo, v. 17, n. 2, Julho/Dezembro de 1994.

GIL, Antônio Carlos. Métodos e técnicas de pesquisa social. 5. ed. São Paulo: Atlas, 1999.

GIL, Antônio Carlos. Como elaborar projetos de pesquisa. 4. ed. São Paulo: Atlas, 2002.

HARVEY, David. Condição Pós- Moderna: uma pesquisa sobre as origens da mudança cultural. 6. ed. São Paulo: Loyola, 1996.

MATOS, Edmundo da Silva Ralfo. Espacialidades em rede: população, urbanização e migração no Brasil contemporâneo. Belo Horizonte: C/Arte, 2005.

PONTARA, Marcela. Português, Contexto, Interlocução e Sentido. v. 1. São Paulo: Moderna. 2010.

PORTAS, Nuno. Novo olhar sobre os movimentos sociais urbanos. In.: BALSA, Casimiro. Relacões Sociais de Espaço: Homenagem a Jean Remy. Lisboa: Edições Colibri, 2006. 93-120.

RICHARDSON, Roberto Jarry et al. Pesquisa Social: métodos e técnicas. 3. ed. São Paulo: Atlas, 1999.

SANTOS, Milton. Por uma Geografia das redes. In.: A natureza do espaço. São Paulo: EDUSP, 2002. p. 261-280.

SANTOS, Milton. Técnica, espaço, tempo: Globalização e meio técnico-científico informacional. São Paulo: Hucitec, 1994.

TELES, Maria Luiza Silveira. Educação: a revolução necessária. $3^{3}$ ed. Petrópolis: Vozes, 1992. 
TELES, Maria Luiza Silveira. Educação sem fronteiras: cuidando do ser. Petrópolis: Vozes, 2003.

TRIVINos, Augusto N. S. Introdução à Pesquisa em Letras/Português: A Pesquisa Qualitativa em Educação: O Positivismo, A Fenomenologia, O Marxismo. São Paulo: Atlas, 1987.

VALENTE, José Armando. Computadores e conhecimento: repensando a educação. Campinas: Unicamp, 1993.

VESENTINI, José Willian. Controvérsias geográficas: epistemologia e política. Confins, n. 2, 2008. Disponível em: <http://dx.doi.org/10.4000/confins.1162>. Acesso em: jun. 2013. 